\title{
An Inheritance Mode of Rural Cultural Heritage Based on Virtual Museum in China
}

\author{
Yuhui Yang $\mathbb{D},{ }^{1}$ Hao Zhang $\mathbb{D}^{2}{ }^{2}$ Mo Chen, ${ }^{1}$ Youbin Jiang, ${ }^{1}$ and Huifang Chai ${ }^{1}$ \\ ${ }^{1}$ Zhejiang University, Hangzhou, China \\ ${ }^{2}$ Hangzhou Normal University, Hangzhou, Zhejiang, China
}

Correspondence should be addressed to Yuhui Yang; zju_edu@zju.edu.cn

Received 11 April 2021; Accepted 16 July 2021; Published 6 August 2021

Academic Editor: Cristian A. Rusu

Copyright (c) 2021 Yuhui Yang et al. This is an open access article distributed under the Creative Commons Attribution License, which permits unrestricted use, distribution, and reproduction in any medium, provided the original work is properly cited.

\begin{abstract}
In China, there is a crisis of rural cultural heritage inheritance due to urbanization. The traditional cultural inheritance modes such as building museums may not satisfy the needs of wide and fast culture transmission, communication, and inheritance. However, the virtual museum may provide new solutions. Nowadays, China has essential social-economic conditions for virtual museum construction but lacks sustainable modes for virtual museums supporting rural cultural heritage inheritance. In this study, we adopted the theoretical analysis method, expert argumentative method, and combined with virtual museum technology analysis to design an appropriate mode for the cultural heritage's inheritance in rural areas. We built a demonstrational virtual museum for the Mt. Mogan government according to this mode, adopted a comparative analysis and questionnaire survey to verify, and assess the application effects of the mode. Results show that the inheritance mode of rural cultural heritage based on the virtual museum has advantages of larger exhibition scale and wider scope of cultural transmission and communication with less input, and this mode's operation is steady and sustainable. The inheritance crisis of rural cultural heritage needs reasonable solutions, and our results can be a guideline for building virtual museums in rural areas to promote wide, fast, and sustainable cultural inheritance.
\end{abstract}

\section{Introduction}

Cultural heritage is a bridge connecting the past and the present $[1,2]$; has important social, economic, scientific, and educational value, which may motivate the emotion of national pride, social belonging and life belief; and even plays an important role in regional stability and social development $[3,4]$. The countryside is the birthplace of Chinese civilization, and rural areas preserve numerous precious original traditional cultural heritages [5]. Rural cultural heritage mainly includes the tangible culture such as local architecture, historical relics, agricultural instruments, and the intangible culture such as folk customs, folk art, and traditional skills $[6,7]$. Rural cultural heritage may reflect local customs, record the development of agriculture history, and carry farmers' homesickness and life belief [8]. Therefore, rural cultural heritage is a basis for understanding and inheriting traditional Chinese culture, and traditional villages and heritage are praised as "living fossils" for Chinese history study [9]. However, the development of industrialization, Land Circulation policy, Cities Construction Campaign, New Rural Construction Campaign, and other factors lead to the crisis in the inheritance of China's rural cultural heritage [10-12]. Much cultural heritage has been damaged, lost, or abandoned, and even some of the cultural inheritance has been disrupted $[13,14]$. Consequently, the number of villages decreased from 3.6 to 0.6 million between 2010 and 2018, and a great deal of rural cultural heritage has been abandoned.

This crisis is not unique in China, but a universal phenomenon around the world. Encouragingly, more and more attention is paid to cultural heritage inheritance, especially in the recent past half-century. For example, the UNESCO and UN World Food Programme established a series of norms for cultural heritage protection by publishing cultural heritage lists and promulgating cultural heritage protection conventions [15], such as the Venice Charter, the Charter of Machu Picchu, and the Charter on the Built Vernacular Heritage. In European countries, cultural heritage protection policies 
have gradually become the highlight of cultural policies, especially in this decade [16]. Many countries adopt a winwin strategy to realize the mutual promotion of cultural heritage protection and economic development [17], for example, through rural tourism or building rural museums. As early as the 1990s, rural tourism has been very popular in the United States, France, Britain, Japan, and South Korea; increasing citizens enjoy countryside life for sightseeing and leisure $[18,19]$. In the late 20th century, Malaysia built a culture museum village to show rural architecture art, traditional wedding, and other rural culture [20]. In addition, the rural museum cluster in North Yorkshire of UK, the museum villages in southern Australia, and the rural cultural auditorium in Jeonju of South Korea are all typical cases of rural tourism to share rural life experiences and save rural cultural heritage [21-23]. In China, the government also launched a series of "Rural Museums Construction" project to protect and inherit rural cultural heritage. In 2013, Zhejiang province launched a "Rural Cultural Auditorium" project to build rural cultural halls with comprehensive functions of cultural heritage, etiquette, and entertainment. In 2014, Shandong province launched a "Rural Memory" project to build rural museums, in order to collect and exhibit the cultural heritage with local characteristics, such as vernacular architecture, agricultural heritage, agricultural production techniques, folk customs, and etiquette [24].

These traditional approaches have made some effects; however, there are also inevitable limits: it is difficult to preserve rural cultural relics for a long term since easy to aging; the construction scale of museums is quite limited by physical space and funds; routine management and maintenance of rural museums or tourist attractions needs a large amount of funds and human resources; it is inconvenient for people to visit from a long distance or in museums' closing time. Therefore, these traditional methods cannot completely satisfy the needs of cross-regional cultural communication, exchange, integration, and innovation, and a new mode is urgently needed to supplement or optimize to the traditional approaches.

Virtual museums may provide a new approach to solve this problem. A virtual museum is a museum that is built in internet cyberspace, using computer technology such as virtual reality and human-computer interaction $[25,26]$. Compared with the traditional museum, virtual museum has obvious advantages: it can vividly present cultural heritage without loss or ruin of the cultural relics [27], the management and maintenance is convenient $[28,29]$, the construction cost is much lower, the visiting is not limited by time and space [30], and increasing visitors like to visit virtual museum [31, 32]. As early as 2004, the Louvre museum has successively developed virtual museums, and the number of Louvre virtual museum visitors even exceeded that of the physical museum in 2012 [33]. In view of the advantages of the virtual museum, some villages worldwide began to use the virtual museum to show rural history, culture, and customs, such as the famous the Red Mill Museum Village in New Jersey, the Smith Museum Village in California, the Jena River Village Museum, and the Online Rural Museum in Britain [30, 34]. In Japan, Ainu, Shirakawa-go, and other rural regions use virtual museums of animation themes to disseminate cultural heritage [35].

However, in China, few virtual museums have been built to inherit rural culture. There may be two main reasons: on the one hand, China used to be a socioeconomicunderdeveloped country; there was a shortage of infrastructure and human resources for the virtual museum construction. On the other hand, a more important factor is the lack of an effective and sustainable mode of rural cultural inheritance based on a virtual museum. Nowadays, with the rapid development of the society and economy of China, these unfavorable conditions have been changed. By the end of $2018,100 \%$ of towns and $98 \%$ of villages had access to the internet, the total number of mobile phones reached 1.57 billion, and the number of $4 \mathrm{G}$ mobile network users reached 1.17 billion; thus, the internet has become the main way to acquire knowledge and information [36]. Besides, the number of skilled virtual-reality technology personnel increased sharply because colleges and training institutions have enlarged enrollment scales and strengthened the training of information technology-related professionals [37]. All these developments make it possible to build a virtual museum to inherit the rural cultural heritage; nevertheless, there is a lack of an effective and sustainable mode of rural culture inheritance based on the virtual museum; it is urgently needed to explore a new mode.

\section{Materials and Methods}

We proposed a rural cultural inheritance mode based on the virtual museum, by three steps: mode designing, mode verification through case empirical research, and mode applying effect assessment.

2.1. Mode Design. Based on the analysis of the current situation of rural cultural heritage, we design an inheritance mode of rural cultural heritage by using the theoretical analysis method and combining with the appropriate virtual museum techniques. Then, we designed the application evaluation indicators of this mode by using the expert argumentative method.

2.1.1. Theoretical Analysis. To take advantage of information technology in wide culture transmission, communication, and integration, some suitable and effective theories should be adopted in design. There are two learning theories that may provide supports, and they are distributed cognition and connectivism. Edwin Hutchins, a cognitive psychologist, proposed that knowledge and cognition are distributed across objects, individuals, artifacts, and tools in the environment, which deploys models of the extended mind by taking as the fundamental unit of analysis "a collection of individuals and artifacts and their relations to each other in a particular work practice" [38, 39]. Distributed cognition suggests that a realistic environment should be created for learning, technology should be adopted to support distributed interaction and collaboration, communication and resource sharing should be laid stress on, and the cultural atmosphere of the learning situation and the learning community are considered very important. Thus, it is an important supporting 
theory for such fields as CSCL, CSCW, HCI, instructional design, distance learning, online professional learning, mobile learning, and massive open online courses [40-42]. Connectivism is a learning theory that explains how internet technologies have created new opportunities for people to learn and share information across the World Wide Web [43]. These technologies include Web browsers, email, wikis, online forums, YouTube, and any other tool which enables the users to learn and share information with other people. Connectivism believed that knowledge keeps growing and evolving, and the faster knowledge develops, the less likely for learners to master all the knowledge. Thus, the approaches which help learners acquire new knowledge are even more important than the knowledge they already own [44]. In recent years, connectivism became the guiding theory for the development of massive open online courses, and push universities around the world to share their best courses $[45,46]$. The two theories may support the rural cultural inheritance mode based on the virtual museum in four aspects, as follows:

(i) The content presentation of the rural virtual museum

Content presentation of the rural virtual museum focuses on realistic presentation effects and suitability of various client devices. The theory of distributed cognition suggests that a realistic environment should be created for learning on the internet; correspondingly, rural virtual museum construction by VR technology can just provide an immersive experiencing environment for visitors, and 3D cultural heritage can help visitors better understand the stories and content carried by the rural cultural heritage. The theory of cognitivism suggests that technology should be adopted to support distributed interaction and collaboration; correspondingly, the rural virtual museum may support visitors to browse rural virtual museum content by mobile phones, computers, iPad, and other devices.

\section{(ii) Resource collection of rural virtual museum}

Distributed cognition and connectivism emphasize the importance of resource sharing, that is, group wisdom promotion by knowledge sharing by users online and offline. However, there are barriers to resource sharing at present, which leads to the common problem of slow collecting and updating of virtual museum resources, and overcoming obstacles of resources sharing is an important approach for resource collection. We propose two ways of resource sharing to promote the efficiency of resource collection: firstly, incentive measures should be adopted to encourage villagers to collect and share the cultural heritage resources, since villagers are the owners and inheritors of local cultural heritage; secondly, internet knowledge acquisition technology should be adopted to automatic aggregate relevant cultural heritage resources to the rural virtual museum.

(iii) Cultural communication of rural virtual museum

Connectivism believes that it is more important to know the approach of acquiring knowledge than to master knowl- edge and suggests that social software and web systems should be adopted to promote learning and knowledge sharing [47]. In the rural virtual museum, there is a vast amount of knowledge connections among cultural heritage to be acquired and learned by visitors, since some rural virtual museum exhibits have connections with other virtual museum exhibits in different rural regions, and extensive content on the internet, by multiple labels such as region, age, classification, application, and similarity. Knowledge connection of cultural heritage may provide convenience for visitors to acquire and disseminate more cultural heritage content and provide opportunities for cross-regional cultural transmission, integration, and innovation. Nowadays, social software is becoming increasingly popular to support communication and resource sharing in China; therefore, social software adoption aiming at sharing and exchanging rural virtual museum cultural heritage may rapidly accelerate the speed and expand the scope of rural culture transmission. Such resources sharing approach may become a major feature of our mode design.

(iv) Management and maintenance of rural virtual museum

Distributed cognition emphasizes the importance of cooperation among individuals in network learning. In China, the overall literacy level of villagers is low, and it is difficult for them to skillfully construct, manage, and maintain rural virtual museums; however, human resources from the external environment may provide help to develop the rural virtual museum, and the working committee can be established with the cooperation of villages and professional institutions such as universities and companies. This working committee is responsible for reasonable coordination between professionals and villagers, so as to ensure the construction and normal operation of the rural virtual museum.

2.1.2. Virtual Museum Technology. The mode designing is supported by virtual museum technology in four aspects, including presentation of the virtual museum, resource collection, cultural communication, and management and maintenance. In the presentation of the virtual museum, such as Autodesk 3ds Max, Unity and 720yun VR panoramic publishing platform were adopted to create $3 \mathrm{D}$ virtual environment, exhibits, animation and interaction, and PHP and HTML5 technologies were used to create a 2D environment and exhibits. In resource collection, on the one hand, PHP and HTML5 technologies were adopted directly to upload resources to the virtual museum; on the other hand, LocoySpide technology was used to automatically collect internet resources and gather them to the virtual museum. In cultural communication, PHP/HTML5 technology and WeChat software are adopted to realize the communication of cultural heritage resources among visitors. In management and maintenance, PHP and HTML5 technologies were used to develop management system and manage and maintain all resources of the virtual museum. Finally, Aliyun technology was used to deploy the virtual museum. An overview of these technologies is shown in Table 1. 
TABLE 1: The development software and technology of virtual museum.

\begin{tabular}{|c|c|}
\hline Software/language & Introduce \\
\hline Unity & $\begin{array}{c}\text { Unity is a world-famous game development platform for creating and operating interactive, } \\
\text { real-time } 3 \mathrm{D} \text { content }\end{array}$ \\
\hline LocoySpide & $\begin{array}{c}\text { LocoySpide is currently China's largest number of users of the internet data capture, } \\
\text { processing, analysis, and mining software. }\end{array}$ \\
\hline 720yun VR panoramic publishing platform & $\begin{array}{l}\text { 720yun VR panoramic publishing platform is the largest SaaS service platform } \\
\text { providing VR panorama production, release, and display services in China }\end{array}$ \\
\hline WeChat & The most popular social software in China \\
\hline PHP/HTML5 & Hypertext Preprocessor/ HyperText Markup Language 5.0 \\
\hline Autodesk 3ds Max & 3D modeling and rendering software for design visualization, games, and animation \\
\hline Aliyun & China's largest cloud service platform \\
\hline
\end{tabular}

2.1.3. Expert Argumentation. The mode we proposed was evaluated by 10 experts in education, folklore, and museology. The evaluation model of the three dimensions: structure-process-result proposed by Dervers is adopted, and the SMART (specific, measurable, attainable, relevant, time-based) principle for performance index selection was obeyed [48]. After evaluating, the mode was modified according to experts' recommendations. The evaluation indicators are shown in Table 2.

2.2. Case Research. We built a demonstrational virtual museum for Mt. Mogan Government according to the rural cultural inheritance mode based on the virtual museum. Mogan community is the village community where the government of Mt. Mogan town is located, in Deqing county, Huzhou city, Zhejiang province. It is a typical area which needs rural culture protection and inheritance; the diligent ancestors and numerous historical celebrities have left abundant precious cultural heritage; however, there are crisis of local cultural protection, inheritance, and transmission with the "construction of the new countryside," and a new protection and inheritance mode is urgently needed for rural cultural heritage. Mt. Mogan Government has a long-term scientific research cooperation relationship with our research team. The government hopes to support the local cultural protection and inheritance through the use of the latest research results by research teams, so it is willing to try the mode we proposed. They are willing to provide local cultural heritage resources and mobilize villagers to assist our research team to participate in the construction of the virtual museum. The funding for the virtual museum project comes from the previously mentioned the Ministry of Education Humanities and Social Sciences Fund.

2.3. Application Effect. In order to assess the effectiveness of the mode we proposed, we assessed input-output and user's experience of Mt. Mogan rural virtual museum through a comparative analysis between the virtual museum and traditional physical museum. In order to analyze the sustainability of the mode, we designed a questionnaire from the perspective of team members' feelings, satisfaction, and willingness, to investigate team members' continued participation.
2.3.1. Input-Output Comparison of Mt. Mogan Rural Virtual Museum and the Physical Museum. We adopted a comparative analysis to assess input-output between the virtual museum and village cultural auditoriums. The cultural auditoriums of Qinlao, Houwu, Ziling, and Dongshe are very famous village-level physical museums, which have contributed to the protection and inheritance of local rural cultural heritage. Taking the well-known Qinlao village cultural auditorium as an example, we made a comparative analysis with the Mt. Mogan rural virtual museum. The main input indicators included space occupation, construction time, capital cost, and major human resources. The main output indicators included museum space, number of exhibits, opening time, and number of visitors.

\subsubsection{Users Experience of Mt. Mogan Rural Virtual Museum.} In order to investigate the user experience of the Mt. Mogan virtual museum, we conducted a questionnaire survey, and 80 visitors who visited the Mt. Mogan virtual museum and 80 visitors who visited the Qinlao cultural auditorium were investigated. The two groups had basically similar demographic characteristics, including age, gender, and education level. The main indicators of the questionnaire included universality of content classification, willingness of users to participate, immersion of virtual museums, convenience of visiting, knowledge acquisition, and satisfaction degree of experience.

2.3.3. Team Members' Feelings, Satisfaction, and Willingness. We designed a questionnaire from the perspective of team members' feelings, satisfaction, and willingness, in order to investigate the sustainability and feasibility of the mode. The main content of the survey included satisfaction with the mode, willingness to participate, satisfaction of economic income and teamwork corporation, and sense of achievement. The survey subjects included 40 participants.

\section{Results}

3.1. Rural Cultural Inheritance Mode Based on Virtual Museum. The mode of rural cultural inheritance mainly based on virtual museum includes two parts: the operation structure and the content classification structure of rural cultural heritage inheritance. 
TABLE 2: The evaluation indicators of rural cultural inheritance mode based on virtual museum.

\begin{tabular}{|c|c|c|}
\hline First-level indicators & Second-level indicators & Third-level indicators \\
\hline \multirow{6}{*}{ Structure } & \multirow{3}{*}{ Content framework } & (i) Rationality of rural cultural heritage classification \\
\hline & & $\begin{array}{l}\text { (ii) Coverage and comprehensiveness of the content framework of the } \\
\text { rural virtual museum }\end{array}$ \\
\hline & & (iii) Universality of the content framework of rural cultural heritage \\
\hline & \multirow{3}{*}{ Organizational structure } & (i) Personnel cooperation of rural virtual museum \\
\hline & & (ii) Sustainability of operating funds for rural virtual museum \\
\hline & & (iii) Availability of network and equipment for rural virtual museum \\
\hline \multirow{9}{*}{ Process } & \multirow{3}{*}{ Resource collection } & (i) Efficiency of rural cultural heritage resource collection \\
\hline & & (ii) Universality of rural cultural heritage resource collection \\
\hline & & (i) Immersion of presentation of rural virtual museum \\
\hline & \multirow[t]{2}{*}{ Resource presenting } & (ii) Compatibility for the different client terminal \\
\hline & & (iii) Convenience of exhibits browsing \\
\hline & \multirow{4}{*}{$\begin{array}{l}\text { Rural virtual museum } \\
\text { management and maintenance }\end{array}$} & (i) Reliability of resource screening \\
\hline & & (ii) Convenience of resource management \\
\hline & & (iii) Efficiency of resources digital processing of \\
\hline & & $\begin{array}{l}\text { (iv) Incentives and constraints for the long-term operation and } \\
\text { maintenance of the rural virtual museum }\end{array}$ \\
\hline \multirow{5}{*}{ Result } & \multirow{2}{*}{ Cultural heritage dissemination } & (i) Convenience of visiting the rural virtual museum \\
\hline & & (ii) Accessible of knowledge \\
\hline & Cultural heritage protection & (i) Effectiveness of cultural heritage protection \\
\hline & \multirow[b]{2}{*}{ Cultural inheritance and innovation } & (ii) Knowledge connection of similar cultural heritage contents \\
\hline & & $\begin{array}{l}\text { (iii) Cultural heritage integration and innovative development of } \\
\text { cross-regional cultural heritage by visiting the rural virtual museum }\end{array}$ \\
\hline
\end{tabular}

\subsubsection{Operation Framework of Rural Cultural Heritage} Inheritance. Based on the theoretical analysis method, virtual museum technology analysis, and expert argumentation method, we design the operation framework of rural cultural heritage inheritance, as shown in Figure 1.

The framework mainly includes four parts of working contents: resource collection, resource presentation, rural virtual museum construction, management and maintenance, and cultural transmission.

Resource collection includes three approaches: villagers and visitors can directly donate the cultural heritage resources they have in the form of old photos, panoramic VR, and 3D models. Commissioners of the working committee guide villagers to collect local cultural heritage resources and upload them to the rural virtual museum after digital processing. Resource collection software automatically mines and collects relevant cultural heritage resources from the internet according to the set theme, and gathers them into the rural virtual museum.

Rural culture resources can be presentation in three types: Web3d, 360 panorama ,and webpage which can present different levels of immersion and meet the requirements for interaction and browsing of client terminals such as mobile phones, computers, and iPads. In rural virtual museum, Web3d and 360 panorama technologies, such as virtual tour, human-computer interaction, 3D model, game, and panorama, are mainly used to present exhibits and virtual spaces, by creating an immersive experience environment for visitors; Webpage technologies, such as picture, video, text, and sound, are mainly used to introduce the details of the exhibits so that visitors can more clearly understand the culture and story of the exhibits.

The construction, management, and maintenance of the rural virtual museums are completed by a working committee composed of professionals from the company or universities and local villagers. The working committee is responsible not only be for the rural virtual museum construction but also for guiding and training the villagers to collect and select cultural heritage and taking charge of management and maintenance. The postsettings are as follows: The publicity specialists in the working committee are responsible for mobilizing villagers to participate in donation and collection of resources. The cultural specialists are responsible for the screening of cultural heritage resources and the excavation of cultural values. Technical specialists are responsible for the development of the rural virtual museum and digital resource processing. The education specialists are responsible for guiding the villagers to participate in the maintenance and management of the virtual museum system. Villagers play multiple roles, such as the resource collector, rural virtual museum manager and maintainer, and cultural heritage inheritor, since they are the owners and inheritors of cultural heritage. The key point of the mode operation is to ensure the positive cooperation between professionals and villagers through the win-win mechanism. For professionals, they can not only gain economic benefits but also obtain professional practice opportunities and improve professional skills. For the 


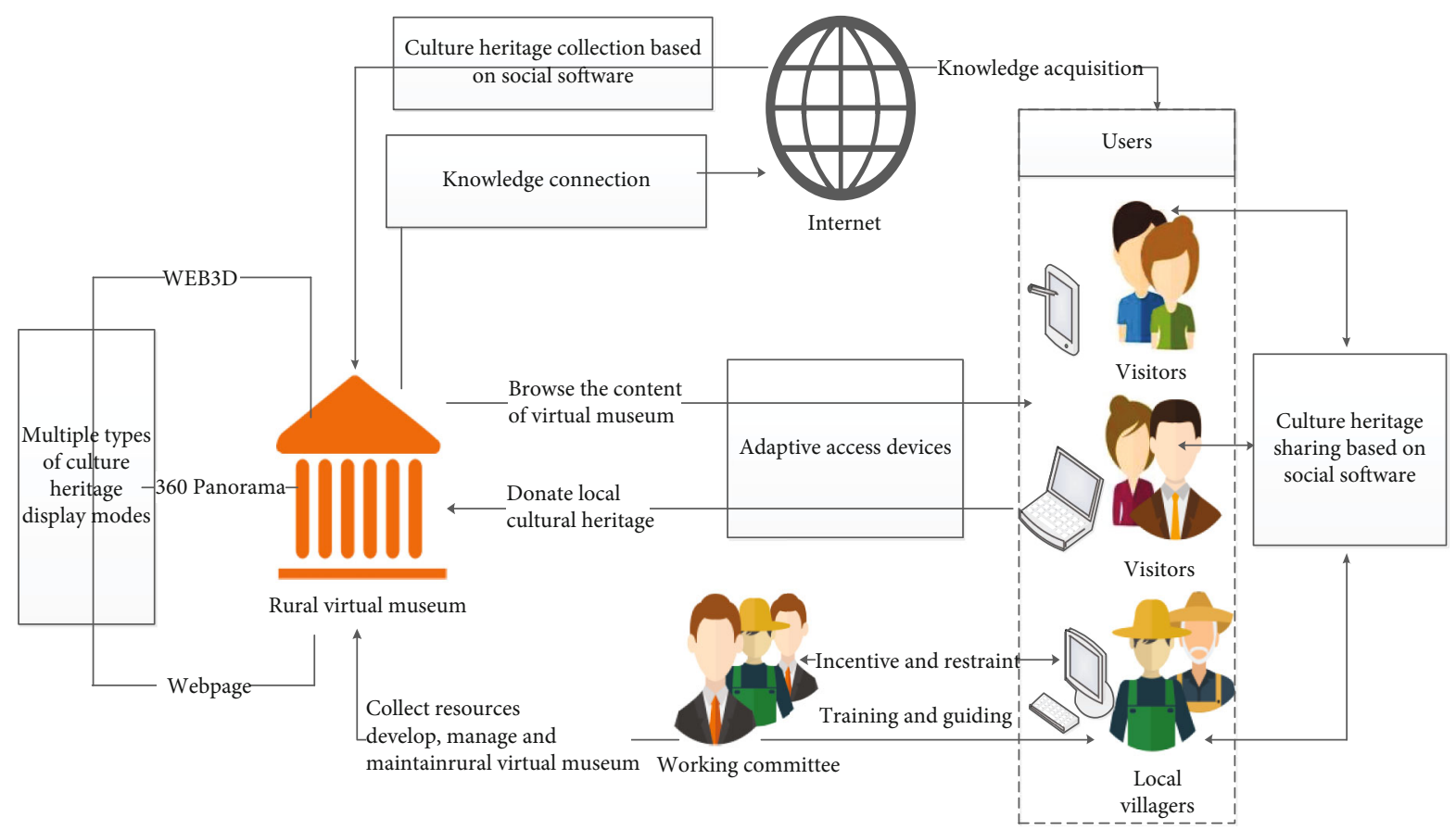

Figure 1: The operation framework of rural cultural heritage inheritance.

villagers, they may get material rewards as well as protect and inherit their culture.

There are three ways to spread rural cultural heritage: Visitors can visit the rural virtual museum at any time by computers, smart phones, and iPads; they unknowingly spread rural cultural heritage through relaxed virtual tour experience in the gamified scenes built by virtual reality technologies such as Web3D and panorama. In the process of virtual tour of the rural virtual museum, visitors can browse more relevant cultural heritage contents on the internet through the knowledge connection of exhibits, which not only expands knowledge zone of cultural communication but also helps promote the integration and development of related cultural heritage. In the rural virtual museum, visitors can share the excellent cultural heritage content they are interested in by social software, such as WeChat and QQ; this mesh of knowledge sharing can more quickly promote the spread of rural cultural heritage.

\subsubsection{Content Classification Framework of Rural Cultural} Heritage Inheritance. In order to provide a reference for rural cultural heritage resource collection and virtual museum exhibits' classified management, we formulated the content framework of the rural virtual museum, on the basis of investigations, and referred to the list of Chinese cultural heritage [49]. There are eight categories: agricultural heritage, including the material and intangible cultural heritage that supports agricultural production; rural life heritage, including the material and intangible cultural heritage that supports the daily life of villagers; folk customs heritage, including local popular traditional festivals and spontaneously formed folk rules, such as wedding, funeral, one-month celebration for newborn, Dragon Boat Festival, and Spring Festival; traditional architectures, including the local architectural features, such as the style of Ming and Qing dynasties, the style of the Republic of China, the early liberation style, and the modern style; traditional skills, including the featured local production technology of daily necessities, such as traditional weaving, hats, coir raincoat, and straw shoes; folklores, including myths and legends, biographies of celebrities, folk songs, and popular historical stories in local areas and reflecting people's spiritual life; folk snacks, including the local delicious foods, including its ingredients, cooking methods, and eating methods (folk snacks are so popular that the famous TV documentary series "A Bite of China" which puts the spotlight on folk snacks received more than 200 million hits within 8 days); and local landscapes, including beautiful natural scenery such as mountains, rivers, and other man-made sceneries.

3.2. Application Cases. In order to verify the feasibility of the mode, we take the Mt. Mogan area as an example to apply the rural cultural inheritance mode based on the virtual museum. Our research group and local government set up a working committee for rural virtual museum construction and operation, with teachers from the Information Technology Center, the Education College, and the Museum Departments of Zhejiang University. Teachers of information technology center serve as technical specialists, responsible for the development of rural virtual museums and the processing of digital resources. Teachers of education colleges act as the education commissioner, responsible for guiding the villagers to participate in the maintenance and management of the virtual museum system. Teachers of the museum department act as cultural commissioners, responsible for the screening of cultural heritage resources and the excavation of cultural value. Village cadres serve as publicity specialists, responsible for mobilizing villagers to participate in resources donation 


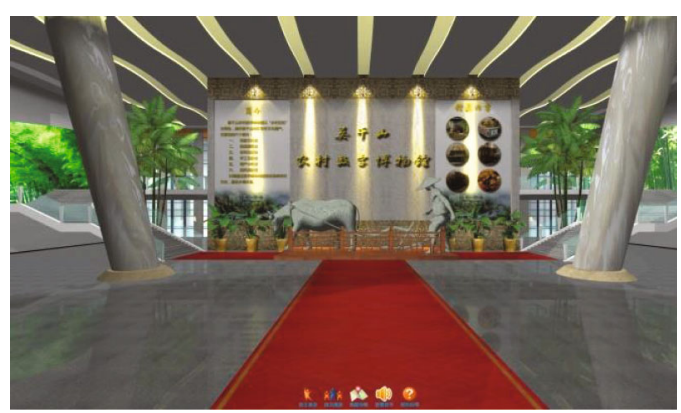

(a)

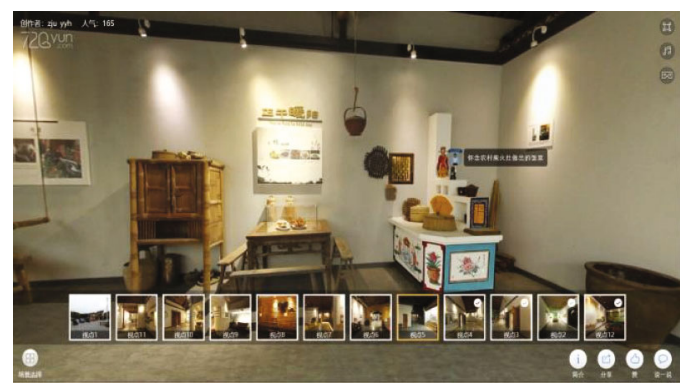

(c)

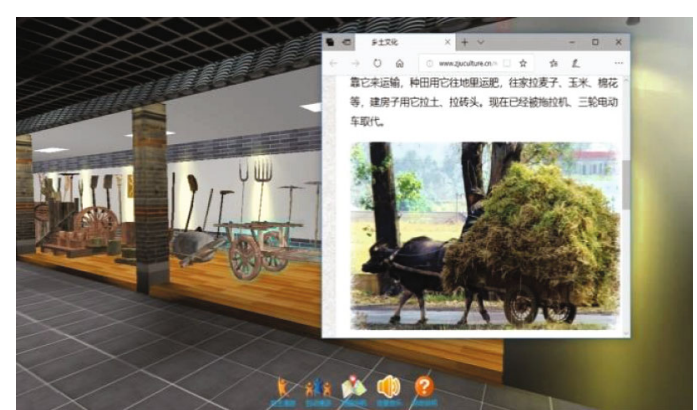

(b)

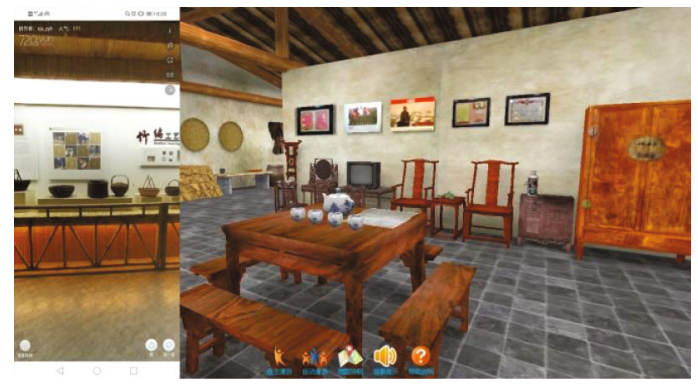

(d)

Figure 2: (a) Mt. Mogan rural virtual museum scene based on Unity. (b) The exhibition introduces of the Mt. Mogan rural virtual museum. (c) Mt. Mogan rural virtual museum scene based on 720yun VR panoramic publishing platform. (d) The display effects of the Mt. Mogan rural virtual museum based on mobile phone and computer.

and collection. The working committee completed the construction of Mt. Mogan rural virtual museum in December 2017, according to the mode we proposed.

3.2.1. Content Design of Mt. Mogan Virtual Museum. The Mt. Mogan rural virtual museum makes a feature of "rural memory", shows the local historical changes, records rural life, and presents the local existing, disappeared and damaged cultural heritage by virtual reality technology. According to the virtual museum mode, the Mt. Mogan rural virtual museum is divided into 8 exhibition halls for farming culture, traditional architecture and rural tife, traditional skill, folk custom, folklore, folk snack, and local scenery. We selected 510 local representative cultural heritages for demonstration.

\subsubsection{Function Realization of Mt. Mogan Virtual Museum.} The Mt. Mogan virtual museum is mainly divided into two modules: visitor and management. It was developed based on current popular technologies and platforms and finally deployed in Aliyun.

(1) Visitor Module. The visitor module mainly includes four parts: roaming in the virtual museum, sharing cultural heritage content, cultural heritage resource's coconstruction, and interactions.

\section{(i) Roaming in virtual museum}

The construction of the Mt. Mogan rural virtual museum is divided into two stages. The first stage is the model and material processing: virtual museum scenes and cultural her- itage models are made by $3 \mathrm{ds}$ Max, and panoramic images of the local cultural heritage were shot with a fish-eye camera and combined into a panoramic space. The second stage is issuing virtual museum: the Mt. Mogan rural virtual museum was released by combining animation script, cultural heritage model, virtual space, and real panoramic space with Unity and 720yun VR panoramic publishing platform. The Mt. Mogan rural virtual museum adopts a first-person gaming perspective to create an immersive experience for visitors. In this virtual museum, visitors can not only observe the exhibits closely but also click on the exhibits to browse the detailed introduction information, as shown in Figure 2. In addition, this virtual museum also adopts the multiresolution adaptive architecture of HTML5, which enables the museum to present the best effect on the screens of different resolutions such as mobile phones, iPads, and computers.

The Mt. Mogan rural virtual museum sets a variety of immersive visiting modes, such as free roaming, automatic roaming, and map roaming. In the free roaming mode, visitors are free to control the movement and rotation of the first-person view and interact with the exhibits as if visiting a real museum. In the automatic roaming mode, visitors are not required to do any operation; the first-person view will automatically guide them to quickly visit collections according to the roaming route of each hall. In the map roaming mode, the Mt. Mogan rural virtual museum provides a navigation map; visitors can quickly jump to the location of their interest to visit, by clicking on the map of the corresponding hot spot, as shown in Figure 3. In order to inspire visitors' nostalgia for the cultural heritage and evoke their rural memories, the Mt. Mogan rural virtual museum will play country music with Jiangnan characteristics during the visit. Country 


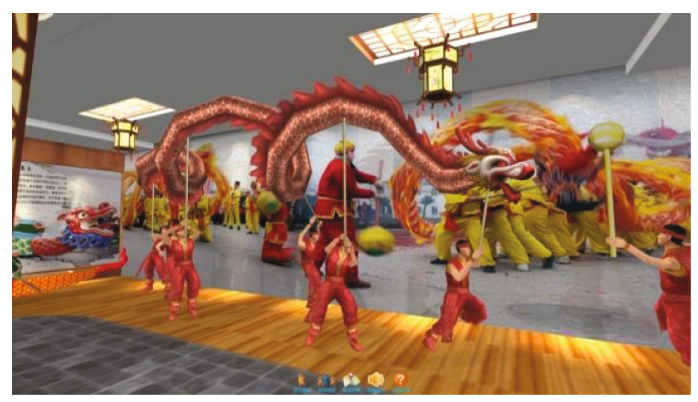

(a)

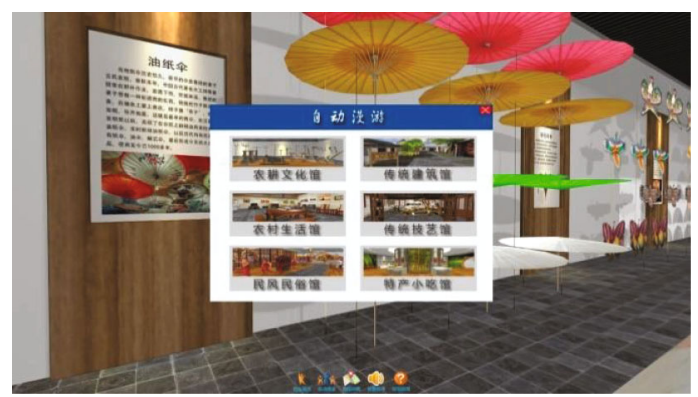

(c)

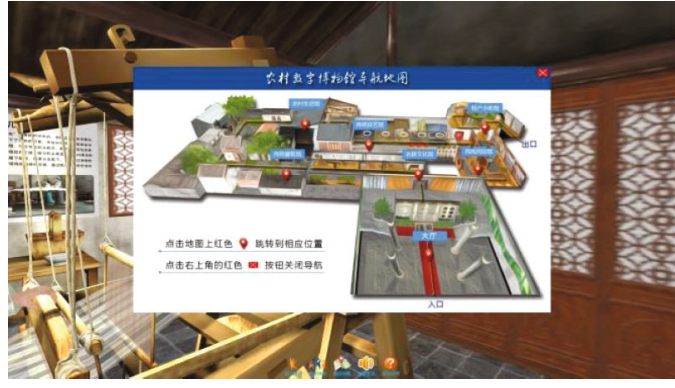

(b)

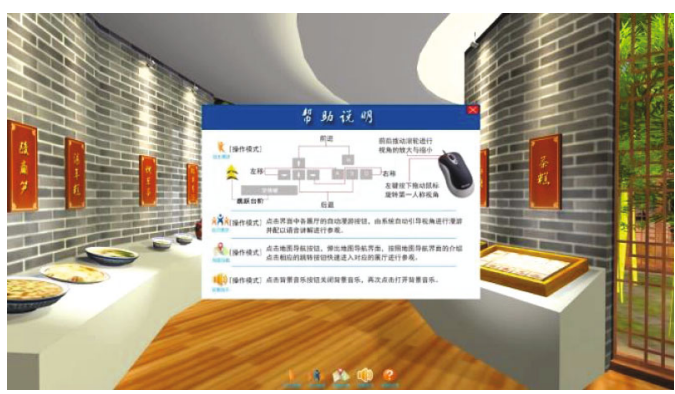

(d)

Figure 3: (a) Free roaming of the Mt. Mogan rural virtual museum. (b) Map roaming of the Mt. Mogan rural virtual museum. (c) Automatic roaming the Mt. Mogan rural virtual museum. (d) Operating instructions of the Mt. Mogan rural virtual museum.

music is combined with the vivid virtual environment, so that visitors achieve an immersive effect. In addition, knowledge connection was established among the cultural heritage content of the Mt. Mogan rural virtual museum and the similar content of cultural heritage websites in different regions according to the same classification, region, and label similarity, which provides convenience for visitors to browse more relevant cultural heritage content.

(ii) Sharing of cultural heritage content based on social software

Using WeChat to share the Mt. Mogan rural virtual museum can realize the rapid spread of cultural heritage. With more than 1 billion worldwide users, WeChat has become the primary tool for people to socialize, talk, and share information in daily life. Thanks to WeChat for providing the sharing integration code, we set up the WeChat QR code for sharing on the page of the Mt. Mogan rural virtual museum. Visitors can scan the QR code and enter the Mt. Mogan rural virtual museum for visiting by their mobile phones. Visitors can also share the content of cultural heritage they are interested in with their friends or WeChat moments, which accelerates the spread of cultural heritage. In WeChat Moments, visitors' friends can make comments or thumb up for wonderful cultural heritage content, which will encourage visitors to participate more actively in the sharing and dissemination of rural cultural heritage content.

(iii) Coconstruction of cultural heritage resource

The coconstruction part of cultural heritage resources was developed by PHP and HTML5. This part is an impor- tant channel for local villagers and visitors to donate their cultural heritage resources. Through this channel, villagers and visitors use mobile phones and computers to upload their own or collected cultural heritage resources to the Mt. Mogan rural virtual museum at any time and any place, in the form of models, pictures, sounds, video, and text. These resources will be displayed in the Mt. Mogan rural virtual museum, after administrator review and processing, which reflects the collaborative mechanism between the members of the working committee and the villagers.

\section{(iv) Interactions of cultural heritage resource}

In the part of communication and interaction, the education specialist of the working committee can discuss with the villagers about the use of information, digital protection technology, resource collection method, and cultural heritage inheritance mode of the virtual museum and train them in management and maintenance skills to ensure the longterm operation of the Mt. Mogan rural virtual museum. Cultural commissioners of the working committee can discuss with visitors about cultural heritage features of different regions, homesickness, and other themes, to enhance visitors' understanding of the cultural heritage content of the Mt. Mogan rural virtual museum.

(2) Management Module. The Mt. Mogan rural virtual museum is jointly managed by the working committee and local villagers. Management and maintenance training courses have been carried out for local villagers by Zhejiang university teachers of the working committee to ensure that they can skillfully manage the Mt. Mogan rural virtual museum. The management module is the core of the Mt. Mogan rural virtual 
TABLE 3: The input-output comparison of the Mt. Mogan rural virtual museum and the Qinlao cultural auditorium.

\begin{tabular}{lccccc}
\hline & $\begin{array}{c}\text { Input } \\
\text { Mt. Mogan rural } \\
\text { Indicators }\end{array}$ & $\begin{array}{c}\text { Qinlao cultural } \\
\text { auditorium }\end{array}$ & Indicators & $\begin{array}{c}\text { Output } \\
\text { Mt. Mogan rural } \\
\text { virtual museum }\end{array}$ & $\begin{array}{c}\text { Qinlao cultural } \\
\text { auditorium }\end{array}$ \\
\hline Space occupied & Cyberspace $100 \mathrm{G}$ & Unused space $200 \mathrm{~m}^{2}$ & Museum space & $2700 \mathrm{~m}^{2}$ & $200 \mathrm{~m}^{2}$ \\
Capital cost & $10,000 \mathrm{CNY}$ & $100,000 \mathrm{CNY}[50]$ & $\begin{array}{c}\text { The number of exhibits } \\
\text { Opening time a day }\end{array}$ & $\begin{array}{c}2410 \\
24 \text { hours }\end{array}$ \\
$\begin{array}{l}\text { Major human resources } \\
\text { Construction time }\end{array}$ & 13 & 14 & Number of visitors & 150,000 person-time & 50,000 person-time \\
\hline
\end{tabular}

museum, which is divided into two parts: content management system and internet resource collection.

\section{(i) Content management system}

The content management system is mainly developed by PHP, which is used to manage all the content of the Mt. Mogan rural virtual museum. In the content management system, the administrator manages all resources by the functions of adding, modifying, deleting, auditing, and publishing, includes the management of $3 \mathrm{D}$ models in the $\mathrm{Mt}$. Mogan rural virtual museum by modifying their parameters such as the scale, rotation, position, and texture. In addition, administrators can interact with visitors, answer their questions, participate in, and manage their topic discussion in the part of communication and interaction.

\section{(ii) Internet resource collection}

We use LocoySpider to collect relevant cultural heritage resources from cultural heritage websites of provinces and cities in China, based on multidimensional keyword comparison and correction rules. LocoySpider is simple professional resource collection software, has powerful content collection and data import functions, which can publish any data collected from the internet to a remote server, and can connect with mainstream and customized content management systems. LocoySpider automatically classifies the collected resources according to the content framework of the Mt. Mogan rural virtual museum and then aggregates them into the database. The content of cultural heritage collected by LocoySpider is reviewed and modified by the administrator and then published in the Mt. Mogan rural virtual museum for visitors to browse. In addition, the cultural commissioner provides professional guidance for the collection, classification, and review of local cultural heritage resources to ensure their representativeness.

3.3. Application Effect of the Mt. Mogan Rural Virtual Museum. The Mt. Mogan rural virtual museum demonstration project was deployed on the Aliyun Server from Dec. 1st, 2017, until Dec. 31st, 2020; its visit has reached more than 150,000 person-times, and 6 professional postgraduate students have been trained in this project.

3.3.1. Input-Output Comparison of Mt. Mogan Rural Virtual Museum and the Physical Museum. In order to assess the effectiveness of the mode we proposed, taking the well- known Qinlao village cultural auditorium as an example, we made a comparative analysis with the Mt. Mogan rural virtual museum, as shown in Table 3. The physical cultural auditorium needs 200 square meters of physical space, while the rural virtual museum only needs $100 \mathrm{G}$ of network space. The rural virtual museum creates 2700 square meters of display space, which is equivalent to the size of thirteen physical cultural auditoriums. The virtual museum has 510 exhibits, which is more than five times as many as that of the cultural auditorium. The virtual museum costs 100,000 CNY, which is only one-tenth of that of the physical cultural auditorium. Major human resources invested in the rural virtual museum are comparable to that of the physical cultural auditorium, but the construction time of the physical cultural auditorium is three times that of the rural virtual museum. As of December 31, 2020, the virtual museum has been open for 48 months with a total number of visitors of 150,000 persontimes. According to Aliyun data, visitors are all over China, the United States, Canada, and other regions. However, the physical culture auditorium has been open for 60 months and has attracted 50,000 visitors, mostly from the surrounding area. The above comparison indicates that the virtual museum may have advantages of larger exhibition scale, wider scope of cultural transmission and communication, with fewer construction costs, and shorter construction time.

3.3.2. Users Experience of Mt. Mogan Rural Virtual Museum. In order to investigate the user experience of the Mt. Mogan virtual museum, we conducted a questionnaire survey, and 80 visitors who visited the Mt. Mogan virtual museum and 80 visitors who visited the Qinlao cultural auditorium were investigated, as shown in Figure 4 . The results indicated that $86.25 \%$ of the visitors maintained that the content classification of the Mt. Mogan virtual museum was universal, while only $56.25 \%$ of the visitors maintained that the content classification of the Qinlao cultural auditorium is universal. 85\% of the visitors expressed their willingness to participate in cultural communication based on the virtual museum, compared with that only $36.25 \%$ of the visitors who visited Qinlao cultural auditorium expressed their willingness to participate. $70 \%$ of the visitors were satisfied with the immersive presentation effect of the Mt. Mogan virtual museum, while that of Qinlao cultural auditorium was 73.75\%. 77.5\% of the visitors were satisfied with the convenience of the Mt. Mogan virtual museum, while only $22.5 \%$ of the visitors were satisfied with the convenience of Qinlao cultural auditorium. $80 \%$ of the visitors were satisfied with the accessible of knowledge in the Mt. Mogan virtual museum, but that of the Qinlao 


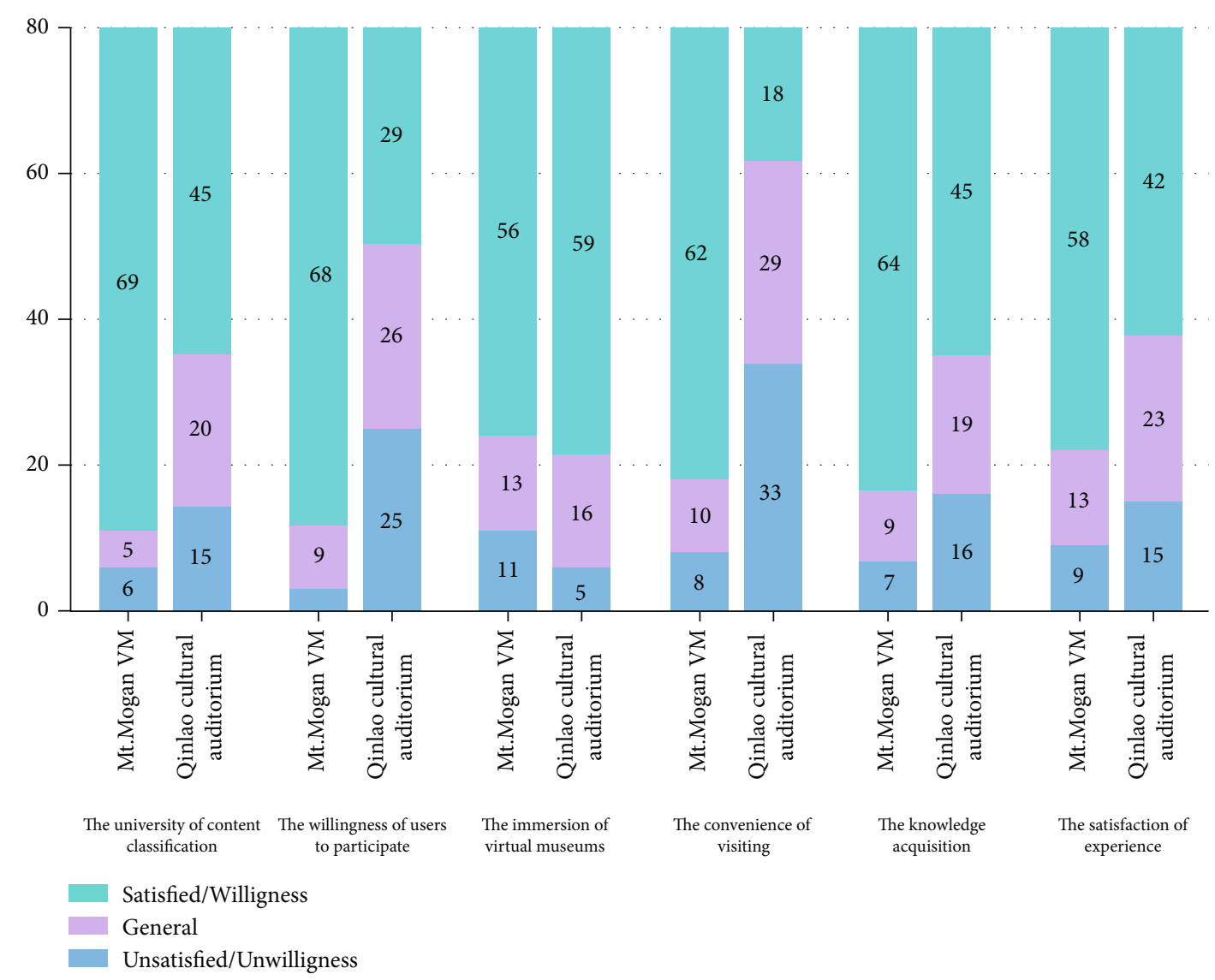

FIgURe 4: User experience comparison for the Mt. Mogan virtual museum and Qinlao cultural auditorium.

cultural auditorium was only $56.25 \%$. $72.5 \%$ of the visitors were satisfied with the overall experience in the Mt. Mogan virtual museum, while that of the Qinlao cultural auditorium was only $52.5 \%$. The above comparison indicated that the universality of content classification, willingness of users to participate, convenience of visiting, knowledge acquisition, and satisfaction degree of experience of the virtual museum may be better than that of the physical museum; however, the disadvantage of immersion is not obvious.

3.3.3. Team Members' Feelings, Satisfaction, and Willingness. We designed a questionnaire from the perspective of team members' feelings, satisfaction, and willingness, in order to investigate the sustainability and feasibility of the mode. The main content of the survey included satisfaction with the mode, willingness to participate, satisfaction of economic income and teamwork corporation, and sense of achievement. The survey subjects included 30 local villagers and 10 university teachers involved in the Mt. Mogan virtual museum project. The survey results show that, for villagers, $76.67 \%$ of the participants were satisfied with the operation mode of the Mt. Mogan virtual museum, $80 \%$ of the villagers were willing to donate the digital cultural heritage resources, $86.67 \%$ of the villagers were willing to participate in rural cultural heritage resource collection and virtual museum operation, $76.67 \%$ of the villagers were satisfied with material incentives, $80 \%$ of the villagers were satisfied with teamwork corporation, and $90 \%$ of the villagers got a sense of achieve- ment in virtual museum construction and operation. For teachers, $80 \%$ of the participants were satisfied with the operation mode of Mt. Mogan virtual museum, 90\% of the teachers were willing to participate in Mt. Mogan virtual museum construction and operation, $60 \%$ of the teachers were satisfied with the economic income, $80 \%$ of the teachers were satisfied with the team members' cooperation, $70 \%$ believe their professional ability was improved in the project, and $80 \%$ of the teachers had a sense of accomplishment in the project. The results show that both villages and teachers have a strong participating willingness, so the mode of the rural virtual museum may be

sustainable and feasible, as shown in Figures 5 and 6.

\section{Discussion and Conclusion}

On the basis of theoretical analysis, technical analysis, and expert argumentation, we proposed a mode to support rural cultural inheritance by using virtual museums. According to this mode, we developed a demonstration virtual museum for Mt. Mogan government in Zhejiang province and investigated its application effect through input-output comparison and questionnaire survey. The application data shows that the virtual museum may have advantages of larger exhibition scale and wider scope of cultural transmission and communication, with fewer construction costs and shorter construction time. Besides, this operational mode is steady and 


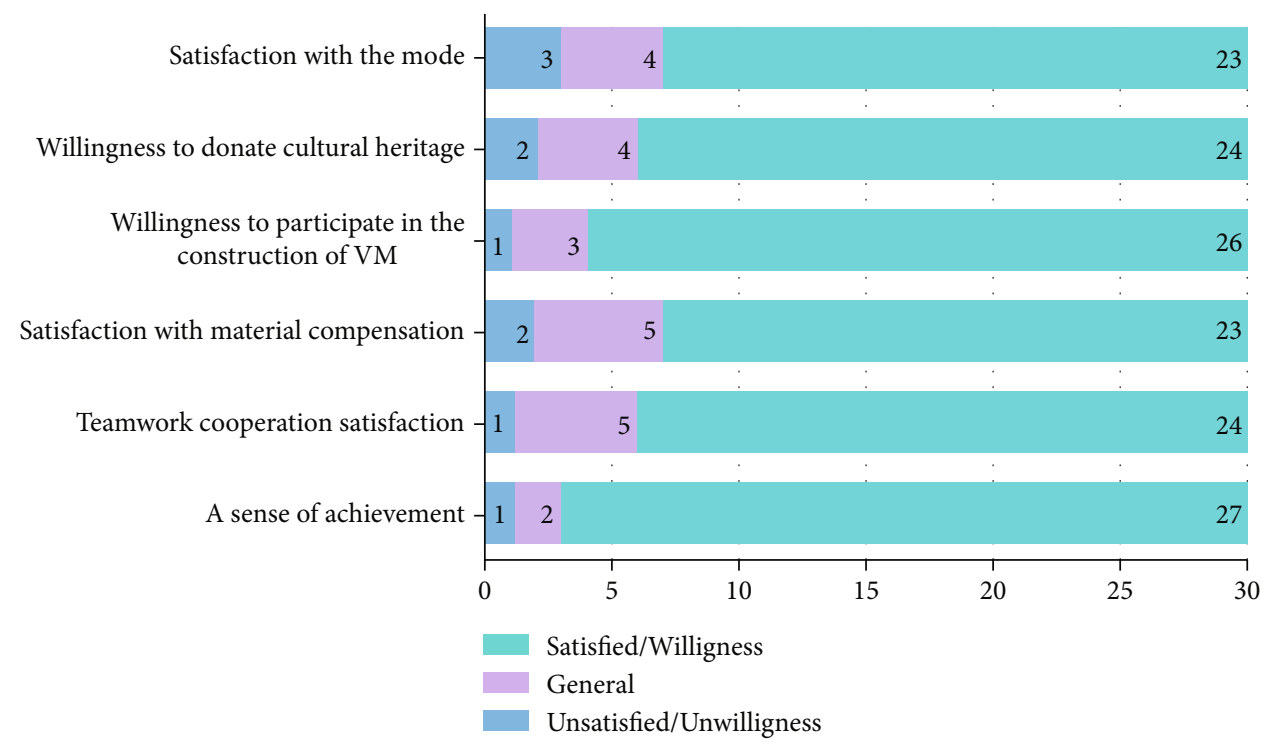

FIGURE 5: Villagers' feeling, satisfaction, and willingness of participating in the Mt. Mogan virtual museum.

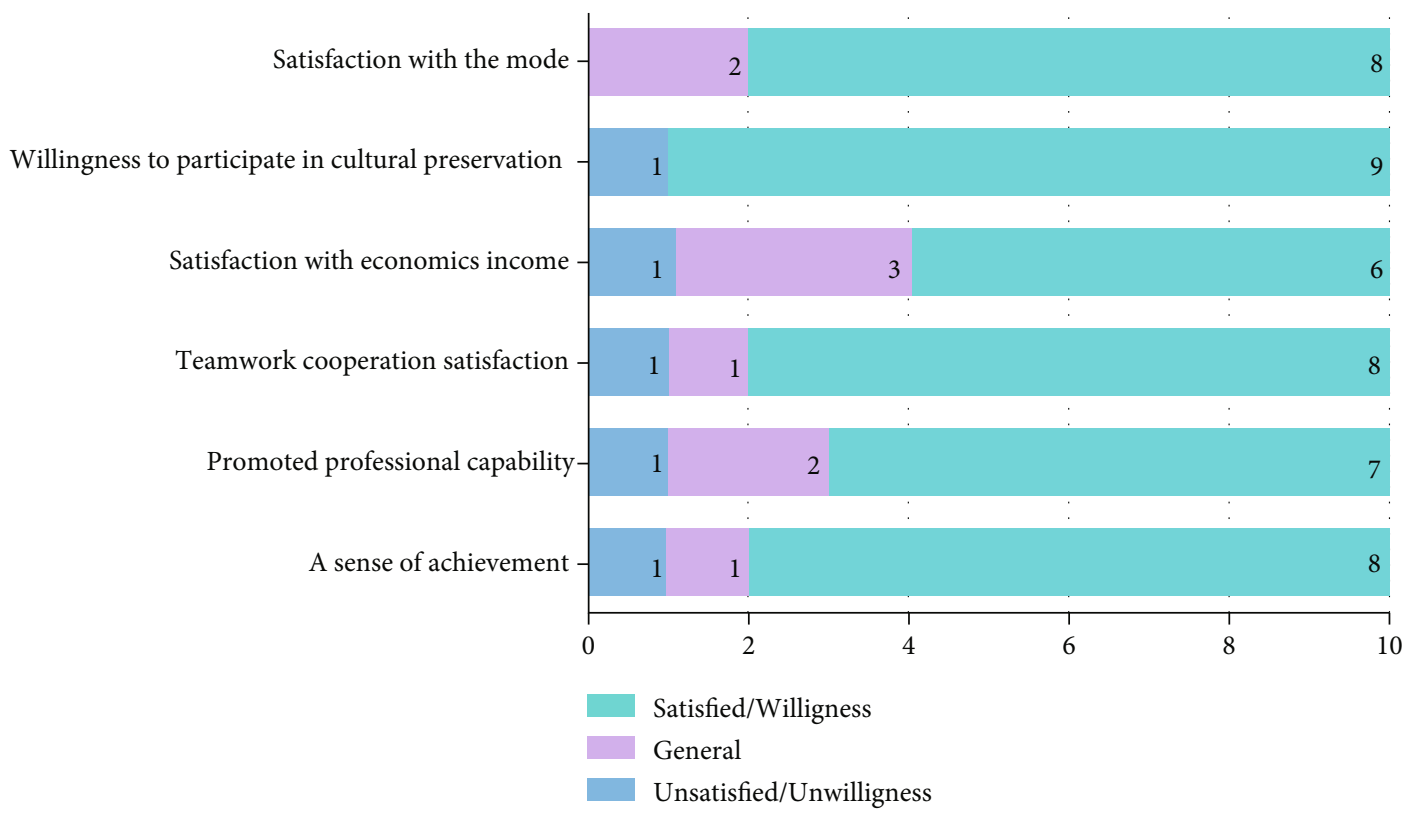

FIgURE 6: Professionals' feeling, satisfaction, and willingness of participating in the Mt. Mogan virtual museum.

sustainable since the team members' feelings, satisfaction, and willingness are quite positive.

The rural virtual museum has advantages in exhibition scale, since it can be built in cyberspace, and the internet may have infinite expansion space theoretically. Furthermore, the virtual museum may far surpass traditional physical museums in exhibits' richness and quantity due to the advantage of content framework and resources collection approach, which may ensure resources supplement and updating. On the one hand, the virtual museum's content has a universal and propagable exhibition content framework. On the other hand, there are more resource collection approach in our mode; resources can be gathered not only by traditional collection and donation but also by automatic col- lection with internet software. The cost of a rural virtual museum is lower than that of the traditional physical museum; it may save huge funds for building construction, decoration, exhibit purchase, exhibit explanation by manpower, routine management and maintenance, etc.

The rural cultural inheritance mode based on virtual museums has significant advantages in fast and widecultural transmission, communication, and inheritance. Visitors can easily visit the rural virtual museum through computers or mobile phones, obtain relevant cultural heritage content on the internet through knowledge connection, and share and exchange cultural heritage content with each other through social software. The Aliyun data indicates that visitors of the Mt. Mogan rural virtual museum are all over 
China, the United States, Canada, and other regions, which not only shows the communication advantage of the virtual museum but also has advantages in cross-regional cultural integration. In order to enlarge the range of cultural exchange, this mode designed a mechanism to overcome the problem of cultural relic's monopoly. Since rural cultural heritage may carry people's emotion of "homesickness", people may be reluctant to donate these precious cultural heritages to traditional physical museums. However, they may have the wiliness to share digital cultural heritage resources for virtual museums without losing their ownership. Incentive measures should be adopted to encourage villagers to collect and share the cultural heritage resources; therefore, people's willingness to participate in our mode is higher than that of physical museums.

The rural cultural inheritance mode based on the virtual museum is steady and sustainable, because the mechanism of win-win cooperation among multiple participants may provide an internal impetus for long-term operation. Internal motivation of the participants and the effective cooperation among the participants are the two essential elements of organizational performance, and in this mode, the participants' satisfaction degrees are high, and their cooperating willingness is strong. Although the villagers do not acquire the knowledge and skills for establishing the virtual museum independently, however, they have a strong affection for rural culture and may gain a strong sense of pride and achievement in participating in virtual museum construction and maintenance. In addition, incentive measures should be adopted to encourage villagers to collect and share the cultural heritage resources. Thus, they may constitute stabilizing force for providing museum exhibit resources, rural culture inheriting, and disseminating. As to professional working committee members, they have the opportunity to give full play to their personal abilities and values, which can stimulate the intrinsic motivation of work. Work system and process set are reasonable; different functional posts were set up for publicity specialist, technical specialist, and education specialist, etc. Participants can select different roles based on their professional skills, management quality and social influence, and other factors. In addition, professionals are also satisfied with the improvement of their abilities, in this project. They trained six graduate students for theoretical and practical innovative experience, in the research fields of museum development, cultural communication, and museum education. Furthermore, a reasonable cooperation mechanism is designed. As face-to-face communication and remote online communication are adopted, the communication and information flow between members are rapid and smooth. In the resolution of intrateam conflicts, professionals of the university coordinate with village cadres and other personnel with a higher level of education as a bridge to realize effective communication with villagers and achieve understanding, acceptance, and collaboration between personnel of different cultural levels.

However, this mode also has some limitations. Although the rural virtual museum mode has advantages over the traditional physical museums, however, the immersion of rural virtual museums is not as good as that of physical museums, because the environment, content, and visiting methods of rural virtual museums are all the simulation of the real world by virtual reality technology, and the cultural emotions and inheritance activities in physical museums are difficult to simulate. In order to overcome this deficiency, in a subsequent study, we will mark the detail location and owner information of cultural heritage in the rural virtual museum, to connect the real-world rural culture heritage with the virtual. For visitors who are not satisfied with the immersive nature of the rural virtual museums, they can visit and learn on the spot according to the location marked and owner information of cultural heritage, to achieve the in-depth user demand experience. In addition, this mode has only been applied and evaluated by the government, Zhejiang University, and local villagers in the Moganshan area; however, cooperation mode with specialized companies still needs to be further verified and improved.

In conclusion, the cultural inheritance mode based on the virtual museum is effective and sustainable for the inheritance of rural cultural heritage, especially suitable for remote areas, and its operation is stable and feasible. This mode has some reference value for the construction and application of rural virtual museums, multisubject collaborative participation mechanism of cultural heritage inheritance, online transmission of cultural heritage, cross-regional cultural integration, and innovative development.

\section{Data Availability}

The basic data of the research came from the references in the paper and the internet, with some links as follows: http://data .stats.gov.cn/search.htm?s=村庄/, https:/www.miit.gov.cn/ gxsj/tjfx/txy/art/2020/art_

f9b061284a1646498f135584d8f78757.html/, and http://zjdq .wenming.cn/zthd/whlt/201704/t20170413_2719358.shtml.

\section{Conflicts of Interest}

The authors declare that they have no conflict of interest.

\section{Acknowledgments}

This research was funded by the humanities and social sciences fund of the Education Ministry of China (No. 15YJCZH205).

\section{References}

[1] F. Cominelli and X. Greffe, "Intangible cultural heritage: safeguarding for creativity," City, Culture and Society, vol. 3, no. 4, pp. 245-250, 2012.

[2] J. M. Makhzoumi, "Unfolding landscape in a Lebanese village: rural heritage in a globalising world," International Journal of Heritage Studies, vol. 15, no. 4, pp. 317-337, 2009.

[3] M. A. Bonn, S. M. Joseph-Mathews, M. Dai, S. Hayes, and J. Cave, "Heritage/cultural attraction atmospherics: creating the right environment for the heritage/cultural visitor," Journal of Travel Research, vol. 45, no. 3, pp. 345-354, 2007. 
[4] Y. L. Huang, "The new countryside cultural construction in the context of intangible cultural heritages protection," Cultural Heritages, vol. 2, pp. 1-5, 2010.

[5] N. Y. Han, Z. Zhang, and S. M. Wang, "A prospective study on the mode of media applications of agricultural heritages communication," Agricultural History of China, vol. 3, pp. 132-142, 2016.

[6] Y. Cao and G. C. Zhou, "The protection challenges and inheritance strategy of the local culture in the process of urbanization plight inheritance strategy," Modern Urban Research, vol. 6, pp. 31-34, 2013.

[7] M. Li and S. M. Wang, "Agro-cultural heritages: what is protected and how to protect," Agricultural History of China, vol. 2, pp. 119-129, 2012.

[8] E. C. Ruijgrok, "The three economic values of cultural heritage: a case study in the Netherlands," Journal of Cultural Heritage, vol. 7, no. 3, pp. 206-213, 2006.

[9] X. Q. Liu and S. M. Wang, "Difficulties and countermeasures of Chinese traditional villages conservation," Agricultural History of China, vol. 4, pp. 99-110, 2015.

[10] Z. F. Guo and H. Zhang, "Impact of change of rural labor force structure on village cultural inheritance," Journal of Northwest A\&F University (Social Science Edition), vol. 13, pp. 116-120, 2013.

[11] National Bureau of Statistics of ChinaAugust 2020, http://data .stats.gov.cn/search.htm?s=村庄/.

[12] C. X. Jie, "The formation of village "empty nest" and "hanging nail community"-based on the case of $\mathrm{X}$ village on the loess plateau. Western development review," in Proceedings of the 11th annual conference of China west development and research association, pp. 141-147, Chengdu, China, 2016.

[13] J. C. Feng, "Dilemma and outlet of traditional villagestraditional villages are another kind of cultural heritages," Forum on Folk Culture, vol. 1, pp. 7-12, 2013.

[14] C. Cui, "The predicament and outlet of legal protection of rural historic and cultural heritages," Journal of Hebei University of Technology (Social Sciences Edition), vol. 10, pp. 55-60, 2018.

[15] A. B. Fromm, "Ethnographic museums and intangible cultural heritage return to our roots," Journal of Marine and Island Cultures, vol. 5, no. 2, pp. 89-94, 2016.

[16] M. Ott, F. M. Dagnino, and F. Pozzi, "Intangible cultural heritage: towards collaborative planning of educational interventions," Computers in Human Behavior, vol. 51, pp. 13141319, 2015.

[17] T. Ying and Y. Zhou, "Community, governments and external capitals in China's rural cultural tourism: a comparative study of two adjacent villages," Tourism Management, vol. 28, no. 1, pp. 96-107, 2007.

[18] S. Prompayuk and P. Chairattananon, "Preservation of cultural heritages community: cases of Thailand and developed countries. Procedia-Social and Behavioral Sciences," Proceedings of 4th AMER International Conference on Quality of Life, 2016, pp. 239-243, Medan, Indonesia, 2016.

[19] J. Bessière, "Local development and Heritage: traditional food and cuisine as tourist attractions in rural areas," Sociologia ruralis, vol. 38, no. 1, pp. 21-34, 1998.

[20] P. Dellios, "The museumification of the village: cultural subversion in the 21st century," Culture Mandala, vol. 5, no. 1, p. $5848,2002$.

[21] L. Young, "Villages that never were: the museum village as a Heritage genre," International Journal of Heritage Studies, vol. 12, no. 4, pp. 321-338, 2006.
[22] H. Du, "Between national narratives and local narratives: the practice of rural museums in North Yorkshire, UK," Southeast Culture, vol. 6, pp. 91-96, 2017.

[23] J. S. Lee, "Measuring the benefits of the Intangible Cultural Heritage Hall in Jeonju Korea: results of a contingent valuation survey," Journal of Cultural Heritage, vol. 16, no. 2, pp. 236238, 2015.

[24] W. X. Wang, "Thinking about the construction status of "Rural memory" project," Archiv, vol. 8, pp. 9-12, 2015.

[25] J. Andrews and W. Schweibenz, "The Kress study collection virtual museum project, a new medium for old masters," Art Documentation, vol. 17, no. 1, pp. 19-27, 1998.

[26] E. Huhtamo, "On the origins of the virtual museum," in Museums in a digital age, pp. 121-135, Taylor and Francis Group, 2010.

[27] L. Gomes, O. Regina Pereira Bellon, and L. Silva, “3D reconstruction methods for digital preservation of cultural heritage: A survey," Pattern Recognition Letters, vol. 50, pp. 3-14, 2014.

[28] D. Tsichritzis and S. J. Gibbs, "Virtual museums and virtual realities. Hypermedia and Interactivity in Museums," in Proceedings of International Conference on Hypermedia and Interactivity in Museums, pp. 17-25, Pittsburgh, USA, 1991.

[29] S. Styliani, L. Fotis, K. Kostas, and P. Petros, "Virtual museums, a survey and some issues for consideration," Journal of cultural heritages, vol. 10, no. 4, pp. 520-528, 2009.

[30] On-line Collections Access at the Museum of English Rural LifeMarch 2019, https://www.museumsandtheweb.com/ mw2001/papers/bowen/bowen.html.

[31] K. Kabassi, "Evaluating websites of museums: state of the art," Journal of cultural heritage, vol. 24, pp. 184-196, 2017.

[32] "The IMLS National Study on the Use of Libraries, Museums and the Internet," March 2020, http://interconnectionsreport .org/.

[33] J. Pallud and D. W. Straub, "Effective website design for experience-influenced environments: the case of high culture museums," Information \& Management, vol. 51, no. 3, pp. 359-373, 2014.

[34] D. Benyon, B. O'Keefe, and O. Mival, "A blended space for tourism: Genesee Country Cillage \& Museum," in Proceedings of Blended Interaction: A CHI 2013 Workshop, pp. 1-6, Paris, France, 2013.

[35] H. Xu and J. J. Guo, "The application and enlightenment of digital technology in the inheritance of Japanese national culture," Journalism Bimonthly, vol. 6, pp. 47-54, 2014.

[36] In 2018, China's Communications Industry Statistics BulletinJanuary 202, https:/www.miit.gov.cn/gxsj/tjfx/txy/art/2020/ art_f9b061284a1646498f135584d8f78757.html/.

[37] H. B. Gao, "The development status, problems and trends of virtual reality (VR) industry in China," Modern Communication, vol. 39, pp. 8-12, 2017.

[38] E. Hutchins and T. Klausen, "Distributed cognition in an airline cockpit," in Cognition and communication at work, pp. 15-34, Cambridge University Press, 1996.

[39] D. Cognitions, Distributed Cognitions: Psychological and Educational Considerations, Publisher: Cambridge University Press, Cambridge, England, 1993.

[40] J. Hollan, E. Hutchins, and D. Kirsh, "Distributed cognition," ACM Transactions on Computer-Human Interaction, vol. 7, no. 2, pp. 174-196, 2000.

[41] J. Mackey and T. Evans, "Interconnecting networks of practice for professional learning," The International Review of 
Research in Open and Distributed Learning, vol. 12, no. 3, pp. 1-18, 2011.

[42] C. K. Looi, P. Seow, B. Zhang, H. J. So, W. Chen, and L. H. Wong, "Leveraging mobile technology for sustainable seamless learning: a research agenda," British journal of educational technology, vol. 41, no. 2, pp. 154-169, 2010.

[43] G. Siemens, "Connectivism: a learning theory for the digital age," International Journal of Instructional Technology and Distance Learning, vol. 2, pp. 3-10, 2005.

[44] J. G. S. Goldie, "Connectivism: a knowledge learning theory for the digital age," Medical teacher, vol. 38, no. 10, pp. 1064-1069, 2016.

[45] J. Hatami, K. A. Abadi, and A. Delavar, "Development of MOOCs instructional design model based on Connectivism learning theory," The Journal of Medical Education and Development, vol. 12, no. 1, pp. 65-86, 2017.

[46] M. Clarà and E. Barberà, "Learning online: massive open online courses (MOOCs), connectivism, and cultural psychology," Distance Education, vol. 34, no. 1, pp. 129-136, 2013.

[47] Y. M. Wang and Z. T. Zhu, "From connectionism to connectivism: a new orientation of learning theory," China Educational Technology, vol. 3, pp. 5-9, 2006.

[48] K. J. Devers, S. M. Shortell, R. R. Gillies, D. A. Anderson, J. B. Mitchell, and K. L. Erickson, "Implementing organized delivery systems: an integration scorecard," Health Care Management Review, vol. 19, no. 3, pp. 7-20, 1994.

[49] China intangible cultural heritages websiteJanuary 2020, http://www.ihchina.cn/index.html/.

[50] Deqing civilization netSeptember 2020, http://zjdq.wenming .cn/zthd/whlt/201704/t20170413_2719358.shtml. 